\title{
Ultrastructure of the pharyngeal filter of the appendicularian Oikopleura vanhoeffeni: implications for particle size selection and fluid mechanics
}

\author{
Don Deibel $^{1} \&$ C. V. L. Powell ${ }^{2, *}$ \\ ${ }^{1}$ Newfoundland Institute for Cold Ocean Science, and Marine Sciences Research Laboratory, Memorial University \\ of Newfoundland, St. John's, Newfoundland A1C 5S7, Canada \\ ${ }^{2}$ Department of Biology, Memorial University of Newfoundland, St. John's, Newfoundland A1C 5S7, Canada
}

\begin{abstract}
It has now been established that, contrary to several recent reports, it is the pharyngeal filter of oikopleurids that removes food particles from suspension rather than the food-concentrating filter. Although the ultrastructure of the food-concentrating filter of several oikopleuric species has been described, nothing is known of the ultrastructure of the pharyngeal filter. We studied the pharyngeal filter of Oikopleura vanhoeffeni using the transmission electron microscope. Mean pore size $(3.26 \times 6.35 \mu \mathrm{m})$ and fiber diameter $(203 \mathrm{~nm})$ of the pharyngeal filter were surprisingly large, but mean width-to-length ratio of the pores $(0.55)$ and porosity of the filter $(91 \%)$ were similar to values for pharyngeal filters of ascidian and thaliacean tunicates. There was no evidence of fine microfibers between the thick fibers. Using the cumulative frequency distribution of pore width of the pharyngeal filter, we predict that particles of 2.4 to $5.8 \mu \mathrm{m}$ nominal size will be retained with $50 \%$ efficiency, and that particles of 4.4 to $6.0 \mu \mathrm{m}$ nominal size will be retained with $100 \%$ efficiency (values from 4 individuals). Particles the size of suspended bacteria $(0.5 \mu \mathrm{m})$ will be retained with less than $10 \%$ efficiency. Pressure drop across the pharyngeal filter was about $0.14 \mathrm{~mm} \mathrm{H}_{2} \mathrm{O}$, which is similar to values for mucous-net suspension feeders with ciliary pumping mechanisms.
\end{abstract}

\section{INTRODUCTION}

Small phytoplankton and bacteria often dominate primary production of dissolved and particulate organic matter in marine ecosystems. This has led to increased interest in the feeding biology of mucous-net suspension feeders (primarily pelagic tunicates among the plankton), because it has been assumed that they consume particles of this size efficiently (Harbison \& Gilmer 1976, King et al. 1980, Alldredge \& Madin 1982, Mullin 1983).

Oikopleura vanhoeffeni is an appendicularian tunicate which is abundant in the cold waters surrounding Newfoundland. Oikopleurids concentrate the food suspension using a complex mucopolysaccharide structure which they secrete known as the 'house' (Alldredge 1977, Deibel in press). The house of most

\footnotetext{
- Present address: Department of Psychology, Dalhousie Uni-
} versity, Halifax, Nova Scotia B3H 4J1, Canada species contains coarse incurrent filters which prescreen the incoming water and prohibit large and spinous particles from entering and fouling the fine, internal food-concentrating filter. The food suspension is concentrated in the food-concentrating filter, where much of the incoming water is pumped through mucous mesh of small pore size (Deibel et al. 1985, Deibel in press). Recently, the food-concentrating filter has been thought to remove food particles from suspension and thus to determine the size composition of the diet (see references in Jørgensen 1984). This is a misrepresentation of the function of this filter (Jørgensen 1984). The concentrated food suspension is drawn from the food-concentrating filter and through the pharyngeal filter by ciliated spiracles in the floor of the pharyngeal cavity. The pharyngeal filter removes food particles from suspension by sieving and adhesion (Deibel in press). Thus, the ultrastructural characteristics of the pharyngeal filter (i.e. pore size and fiber diameter) ultimately determine the size composition of the diet. 
Although the ultrastructure of the food-concentrating filter of a few oikopleurid species has been described (Flood 1978, 1981, Deibel et al. 1985), nothing is known of the ultrastructure of the pharyngeal filter. We are interested in the fluid mechanics and energetics of feeding of Oikopleura vanhoefferi. Our goal was to determine the pore size and fiber diameter of the pharyngeal filter of $O$. vanhoeffeni using the transmission electron microscope. The results have led us to speculate on the fluid mechanics of the pharyngeal filter and to predict its particle size retention characteristics.

\section{METHODS}

Individual Oikopleura vanhoeffeni were collected in $500 \mathrm{ml}$ glass jars by SCUBA divers from April to June 1985 in Logy Bay and Witless Bay, Newfoundland, Canada. Jars containing specimens were held in a flowing seawater bath at ambient temperature in the laboratory. Food offered was natural particulate matter collected along with the oikopleurids. Within $18 \mathrm{~h}$ of collection, feeding individuals were fixed and their pharyngeal filters were removed for observation with the transmission electron microscope.

Each oikopleurid inside its house was transferred into a $100 \mathrm{ml}$ beaker which was placed in an ice-bath on the stage of a dark-field stereomicroscope equipped with a 'cold' fiber-optic light source. Individual trunk length was measured with an ocular micrometer to the nearest $0.03 \mathrm{~mm}$. Oikopleurids were fed either Isochrysis galbana or Chaetoceros calcitrans to make the pharyngeal filter visible (Fig. 1). Ice-cold $2 \%$ glutaraldehyde with $0.1 \mathrm{M}$ Sorensen's phosphate buffer ( $\mathrm{pH} 7.2$ ) was infused slowly into the incurrent filters of feeding individuals. They were then transferred to fresh fixative for a minimum of $2 \mathrm{~h}$, washed in buffer, and post-fixed for $1 \mathrm{~h}$ in ice-cold phosphate-buffered $1 \% \mathrm{OsO}_{4}(\mathrm{pH} 7.2)$.

The pharyngeal filter was removed from fixed individuals by making a medial incision along the dorsal surface of the trunk from the mouth to the stomach, followed by a latero-ventral incision from the stomach to each spiracle. The epithelium was removed from the trunk, exposing the endostyle, pharynx and esophagus. The pharynx and endostyle were excised from the trunk by making an incision across the esophagus and removing the epithelium surrounding the endostyle. Next, an incision was made between the dorsal laminae exposing the pharyngeal filter which remained attached to the endostyle. The endostyle was macerated gently using fine-tipped probes and the pharyngeal filter removed. The filter was suspended in a drop of $70 \%$ ethanol and was placed on Butvar-

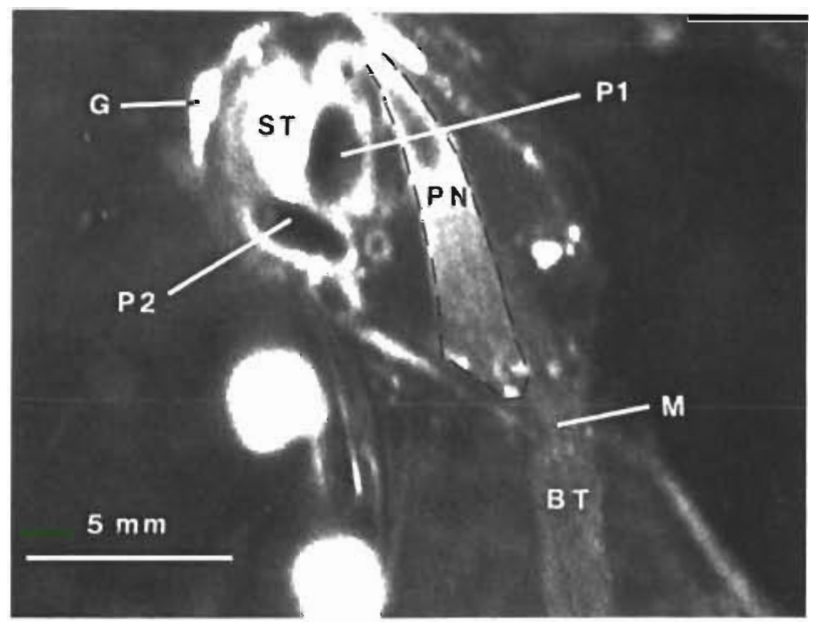

Fig. 1. Oikopleura vanhoeffeni. Light micrograph of an individual feeding in the laboratory. The pharyngeal net $\left(\mathrm{PN}_{\text {; }}\right.$ limits shown by dotted line) was made visible by offering a high concentration of Isochrysis galbana. Notice the newly formed fecal pellet in the upper intestine (P1), and an older pellet in the lower intestine (P2). The dark area in the upper pharyngeal net near the esophagus remains unidentified, but is probably a section of net to which no phytoplankton adhered. M: mouth; G: gonads; ST' stomach; BT: buccal tube

coated, 200 mesh copper grids. Preparations were airdried overnight and viewed with a Zeiss EM9A or Zeiss EM109 transmission electron microscope. These procedures certainly introduced fixation artifacts, but their magnitude was difficult to determine and was beyond the scope of this work. Flood (1978) has discussed possible sources of artifacts in electron microscope studies of mucous filters.

Of the 53 oikopleurids examined, transmission electron micrographs containing filters that could be measured were obtained from 4 individuals. The protocol for measuring filter ultrastructure was similar to that used previously (Deibel et al. 1985). However, the pharyngeal filter was more delicate than the foodconcentrating filter. Only rarely was mesh found that had rectangular structure. We assumed that unmanipulated pharyngeal filter has rectangular mesh because of its ubiquity in all tunicates (Flood 1978, 1981, Monniot 1979, Flood \& Fiala-Médioni 1981, Silver \& Bruland 1981, Pennachetti 1984, Deibel et al. 1985). Also, scanning electron micrographs of fecal pellet contents of Oikopleura vanhoeffeni had rectangular mesh in the matrix (Fig. 2; Deibel \& Turner 1985). Thus, for measurement we selected by eye those areas of the electron micrographs with rectangular pores (see 'Results'). Pore width was defined as the lesser dimension of a given pore. The pore width-tolength ratio was defined after Wallace \& Malas (1976), and the $\%$ open area (i.e. porosity) of the filter was calculated as previously for the food-concentrating fil- 


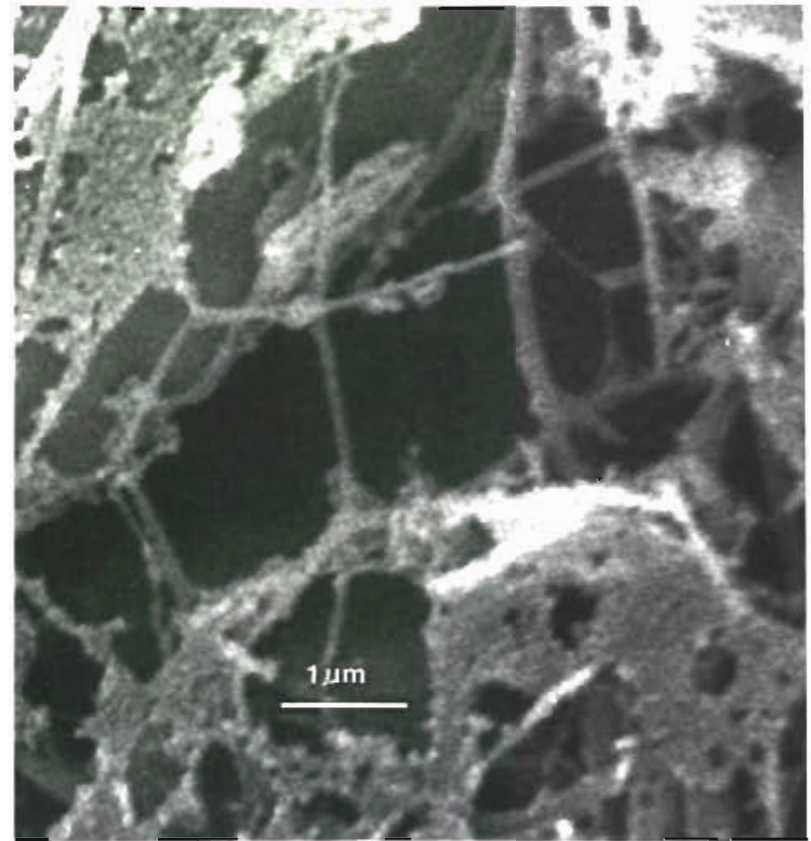

Fig. 2. Oikopleura vanhoeffeni. Scanning electron micrograph of fecal pellet contents of an individual that had been feeding in the laboratory on naturally occurring particulate matter. Notice the rectangular mesh in the matrix of the pellet (enlargement from Fig. 5b of Deibel \& Turner 1985)

ter (Deibel et al. 1985). Often only pore length or width could be measured on a given electron micrograph, so all data were reduced to mean values. Source of variability in mean pore size and fiber diameter was assessed using model II, unbalanced, nested analysis of variance (Ray 1982, Sokal \& Rohlf 1982).

\section{RESULTS}

The pharyngeal filter was composed of fibers arranged in a rectangular pattern (Fig. 3a). Intersecting fibers did not differ in diameter, and there were no nodes where fibers crossed. There were no fine microfibers between thick fibers (Fig. 3b). Points where fibers crossed appeared dark, indicating that they were superimposed (Fig. 3c). Much variation of the rectangular pattern was apparent in larger sections of the filter (Fig. 3c). We assumed that this variation was due to manipulation of the filter during its removal from the oikopleurid (see 'Methods'). Many fibers formed branches (Fig. 3a, c), and there was evidence of light and dark bands within some fibers (Fig. 3c).

Pore width ranged from 0.90 to $6.00 \mu \mathrm{m}$, while pore length ranged from 1.96 to $14.3 \mu \mathrm{m}$ (Table 1). The major source of variation in mean pore width and length was between electron micrographs within individuals $(p<0.001)$, with no additional variance

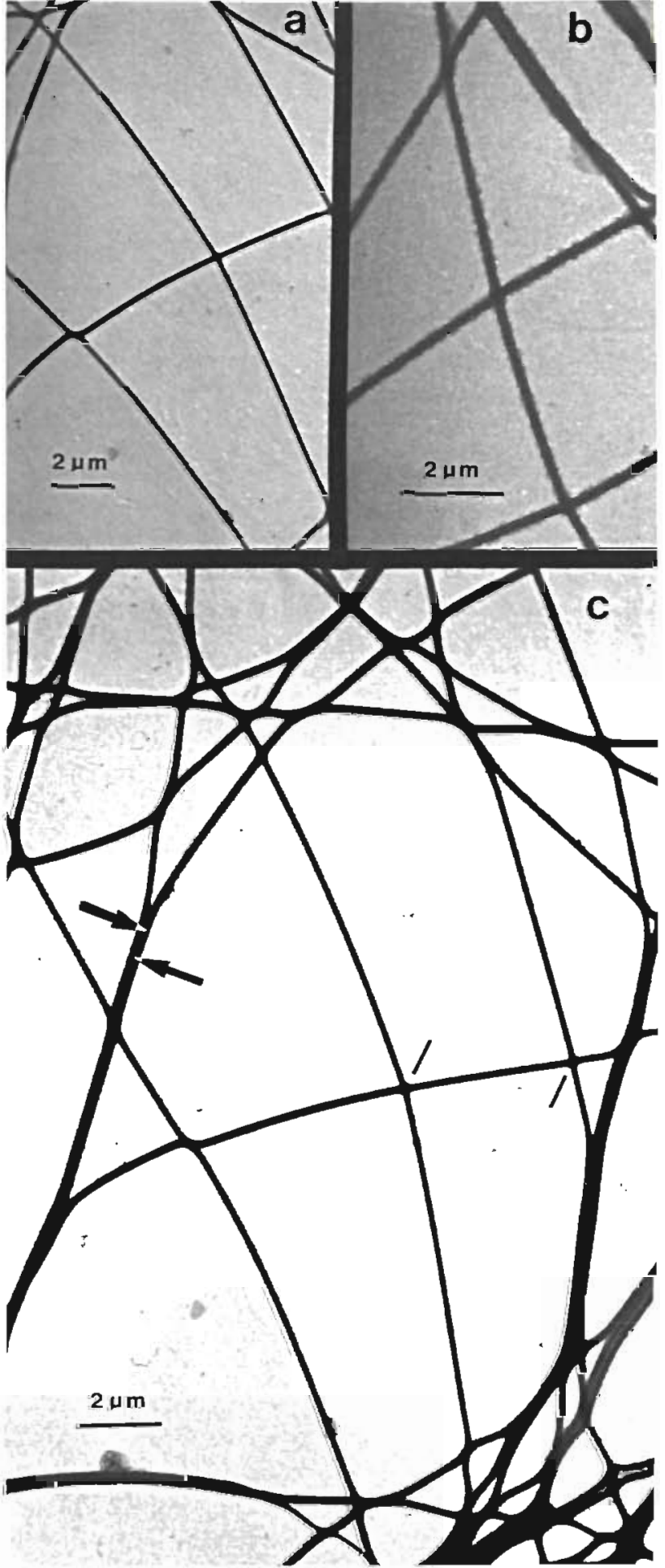

Fig. 3. Oikopleura vanhoeffeni. Transmission electron micrographs of the pharyngeal mucous filter. (a) Segment of the filter with relatively rectangular pores. Notice the absence both of nodes on the fibers and of fine microfibers between the thick fibers. (b) Higher magnification view of rectangular pores. (c) Wider view at lower magnification of the area of filter from which (a) was taken. Notice the light and dark bands within the fibers (arrows), and the dark fiber intersections (lines) 
Table 1. Oikopleura vanhoeffeni. Mean pore length, pore width, and fiber diameter $( \pm S D)$ of the pharyngeal mucous net. Values below are $[\mathrm{n}]$ and (range)

\begin{tabular}{|c|c|c|c|c|c|c|c|c|c|}
\hline Individual & $\begin{array}{c}\text { Trunk } \\
\text { length } \\
(\mathrm{mm})\end{array}$ & $\begin{array}{c}\text { Pore } \\
\text { length } \\
(\mu \mathrm{m})\end{array}$ & $\begin{array}{l}\text { Coefficient } \\
\text { of variation } \\
\text { of mean } \\
\text { pore length }\end{array}$ & $\begin{array}{c}\text { Pore } \\
\text { width } \\
(\mu \mathrm{m})\end{array}$ & $\begin{array}{c}\text { Coefficient } \\
\text { of variation } \\
\text { of mean } \\
\text { pore width }\end{array}$ & $\begin{array}{c}\text { Fiber } \\
\text { diameter } \\
(\mathrm{nm})\end{array}$ & $\begin{array}{l}\text { Coefficient of } \\
\text { variation of } \\
\text { mean fiber } \\
\text { diameter }\end{array}$ & $\frac{\text { Pore width }}{\text { Pore length }}$ & $\begin{array}{c}\% \text { Open } \\
\text { area }\end{array}$ \\
\hline 1 & 3.63 & $\begin{array}{c}5.72 \pm 2.49 \\
{[39]} \\
(2.66-9.28)\end{array}$ & 0.44 & $\begin{array}{c}2.80 \pm 1.26 \\
{[52]} \\
(0.90-5.19)\end{array}$ & 0.4 .5 & $\begin{array}{c}176 \pm 43 \\
{[170]} \\
(97-314)\end{array}$ & 0.23 & 0.49 & 91 \\
\hline 2 & 4.50 & $\begin{array}{c}7.39 \pm 1.44 \\
{[8]} \\
(4.99-8.83)\end{array}$ & 0.19 & $\begin{array}{c}4.93 \pm 0.41 \\
{[10]} \\
(4.39-5.75]\end{array}$ & 0.08 & $\begin{array}{c}257 \pm 41 \\
{[47]} \\
(154-330)\end{array}$ & 0.16 & 0.67 & 92 \\
\hline 3 & 2.88 & $\begin{array}{c}4.33 \pm 1.48 \\
{[7]} \\
(1.96-6.97)\end{array}$ & 0.34 & $\begin{array}{c}2.57 \pm 1.32 \\
{[8]} \\
(0.99-4.40)\end{array}$ & 0.51 & $\begin{array}{c}221 \pm 38 \\
{[65]} \\
(130-321)\end{array}$ & 0.17 & 0.59 & 88 \\
\hline 4 & 3.50 & $\begin{array}{c}12.4 \pm 1.83 \\
{[5]} \\
(9.40-14.3)\end{array}$ & 0.15 & $\begin{array}{c}5.40 \pm 1.07 \\
{[6]} \\
(3.24-6.00)\end{array}$ & 0.20 & $\begin{array}{c}294 \pm 15 \\
{[10]} \\
(267-314)\end{array}$ & 0.05 & 0.44 & 93 \\
\hline $\begin{array}{c}\text { Individuals } \\
\qquad 1-4\end{array}$ & & $\begin{array}{c}6.35 \pm 2.97 \\
{[59]} \\
(1.96-14.3)\end{array}$ & 0.47 & $\begin{array}{c}3.26 \pm 1.50 \\
{[76]} \\
(0.90-6.00)\end{array}$ & 0.46 & $\begin{array}{c}203 \pm 54 \\
{[292]} \\
(97-330)\end{array}$ & 0.27 & $\begin{array}{c}0.55 \pm 0.10 \\
{[4]} \\
(0.44-0.67)\end{array}$ & $\begin{array}{c}91 \pm 2 \\
{[4]} \\
(88-93)\end{array}$ \\
\hline
\end{tabular}

between individuals. Based on mean pore sizes the width-to-length ratio ranged from 0.44 to 0.67 (Table 1 ). Because of variability in pore size and shape the coefficient of variation of mean pore width and length was high (Table 1).

Unlike mean pore size, there was a significant component of total variation of mean fiber diameter between individuals ( $p<0.01$; Table 1 ). Fiber diameter ranged from 97 to $330 \mathrm{~nm}$. Using the mean fiber diameter and pore size for each individual, the porosity of the pharyngeal filter ranged from 88 to $93 \%$ (Table 1 ). Mean fiber diameter was less variable than were mean pore width and length (comparison of coefficients of variation; Table 1).

The retention characteristics of pelagic tunicate mucous filters can be predicted by analyzing the frequency and cumulative frequency distributions of pore width by analogy with plankton nets and otter trawls (Cassie 1955, Harbison \& McAlister 1979). Assuming that tunicate filters function as sieves and that any particle larger than a particular pore will be retained by that pore, the retention index, $R$ (that pore width corresponding to particles retained with $50 \%$ efficiency), and the apparent maximum mesh width, AMMW (that pore width corresponding to particles retained with $100 \%$ efficiency), can be used to describe frequency distributions of pore width (Harbison \& McAlister 1979). We have estimated $\mathrm{R}$ and AMMW in 3 ways (Table 2). Since our data sets comprise high resolution measurements of a continuous variable, the first estimates of $\mathrm{R}$ and $A M M W$ are the median (50th percentile) and maximum value (100th percentile) of the relative cumulative frequency distributions (Table 2). The derived ratio $A M M W / R$ is a measure of the steepness of the cumulative frequency distribution of pore width. A filter that has a rapid increase in predicted retention efficiency with increasing particle size will have a low value of the ratio, while a filter that has a more gradual increase in predicted retention efficiency with increasing particle size will have a higher value of the ratio.

In addition, the data were fit to 2 different theoretical frequency distributions, the normal and uniform distributions. Harbison \& McAlister (1979) have discussed the significance of these distributions for establishing a realistic model of the feeding mechanism. The relative cumulative frequency distribution of pore width for Individual 1 resembled that expected for a normal variable (sigmoid curve; Fig. 4), and the null hypothesis that pore width values were normally distributed was not rejected for any of the 4 individuals (Kolmogorov-Smirnoff and Shapiro-Wilk tests, $p>0.20 ;$ Ray 1982). This was so even though the number of measurements of pore width for Individuals 2,3 , and 4 was small (Table 1). Thus, the frequency distributions of pore width can be described uniquely by the mean and standard deviation (see the column of mean pore widths in Table 1), which corresponds to the retention index $(R)$ and selection index (S) of Harbison \& McAlister (1979). AMMW was calculated for each individual for that pore width corresponding to the 95th percentile of the normal distribution (Table 2). We chose the 95th percentile because the normal curve approaches the 100th percentile of the distribution 
Table 2. Oikopleura vanhoeffeni. Predicted retention characteristics of the pharyngeal filter of 4 individuals arranged in ascending order of trunk length. R: retention index $150 \%$ retention efficiency); AMMW apparent maximum mesh width $(100 \%$ retention efficiency). For each individual the first row shows R and AMMW determined from the median (50th percentile) and maximum value (100th percentile) of the original data set; the second row shows values estimated from the normal distribution function, with $\mathrm{R}=$ mean of the distribution and AMMW = pore width at the 95th percentile of the distribution (see 'Results'); and the third row shows values estimated from a least-squares linear regression of relative cumulative frequency vs pore width. The regression equations were solved for those pore widths corresponding to the 50 th and 100th percentiles of the distribution ( $R$ and AMMW respectively)

\begin{tabular}{|ccccc|}
\hline Individual & $\begin{array}{c}\text { Trunk } \\
\text { length }(\mathrm{mm})\end{array}$ & $\begin{array}{c}\mathrm{R} \\
(\mu \mathrm{m})\end{array}$ & $\begin{array}{c}\text { AMMW } \\
(\mu \mathrm{m})\end{array}$ & AMMW/R \\
\hline \multirow{2}{*}{3} & 2.88 & 2.44 & 4.40 & 1.80 \\
& & 2.57 & 4.75 & 1.85 \\
& & 2.30 & 4.50 & 1.96 \\
4 & \multirow{2}{*}{3.50} & 5.78 & 6.00 & 1.04 \\
& & 5.40 & 7.17 & 1.33 \\
& & 5.00 & 7.32 & 1.46 \\
\multirow{2}{*}{1} & \multirow{2}{*}{3.63} & 2.48 & 5.19 & 2.09 \\
& & 2.80 & 4.88 & 1.74 \\
& & 2.76 & 4.98 & 1.80 \\
& \multirow{2}{*}{4.50} & 4.80 & 5.75 & 1.20 \\
& & 4.93 & 5.61 & 1.14 \\
& & 4.85 & 5.62 & 1.16 \\
\hline
\end{tabular}

asymptotically, and calculating a pore width value corresponding to the 100 th percentile led to predicting pore widths of $100 \%$ retention that were beyond the maximum values actually measured. Finally, the relative cumulative frequency distributions were described by a simple linear regression versus pore width (see Fig. 4 for Individual 1). All regression coefficients were significantly different from 0 for each of the 4 individuals $(p<0.05)$. The resulting linear equation describes the cumulative distribution function of a uniform variable (Harbison \& McAlister 1979). The regression equation for each individual was solved for those pore width values at the 50th and 100th percentiles of the distribution, which correspond to $\mathrm{R}$ and AMMW respectively (Table 2 ).

Excluding the anomalous values for Individual 4, both $\mathrm{R}$ and $\mathrm{AMMW}$ increased with increasing trunk length of the oikopleurids (Table 2). Overall, $R$ ranged from 2.4 to $5.8 \mu \mathrm{m}, \mathrm{AMMW}$ from 4.4 to $6.0 \mu \mathrm{m}$, and AMMW/R from 1.0 to 2.1. In all cases these extreme values were from the determination of $\mathrm{R}$ and AMMW derived from the original distributions (i.e. the median and maximum value). Values for Individual 4 were anomalous because of our inability to acquire a suffi-

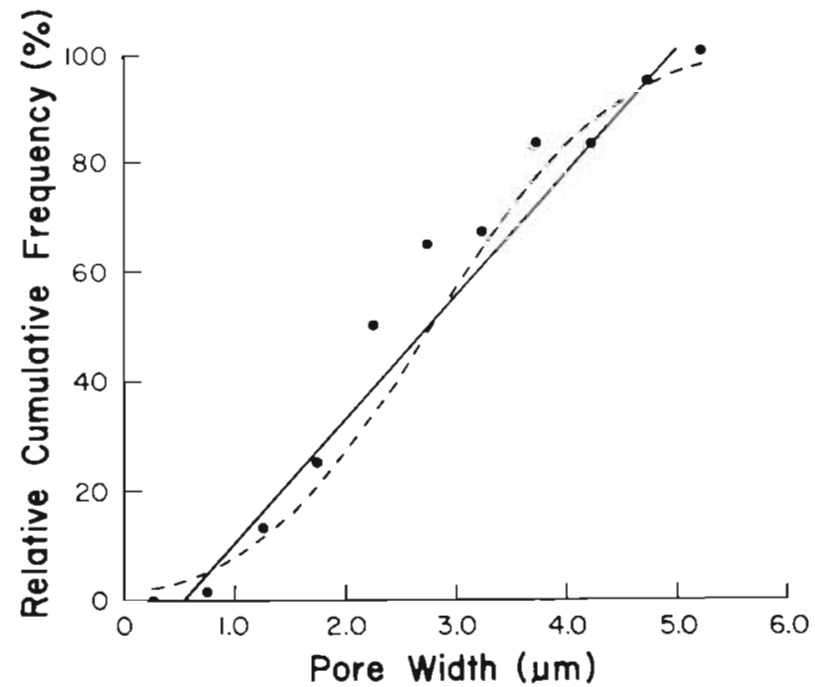

Fig. 4. Oikopleura vanhoeffeni. Relative cumulative frequency distribution (\%) of pore width (um) of the pharyngeal filter for Individual 1, determined from measurements of electron micrographs. Cumulative frequency $(\bullet)$ is plotted at the midpoint of $0.5 \mu \mathrm{m}$ intervals of pore width $(n=52)$. The normal curve (---) was plotted manually using the mean $(2.80 \mu \mathrm{m})$ and standard deviation $(1.26 \mu \mathrm{m})$ of the original data set. This is a different technique to that used by Harbison \& McAlister (1979; probability paper). (-) Least-squares linear regression of relative cumulative frequency (RCF) vs pore width (PW). The regression equation was: $\mathrm{RCF}=22.5 \pm$ $0.78 \mathrm{PW}-12.0 \pm 2.41\left(\mathrm{n}=52, \mathrm{r}^{2}=0.95\right)$. The slope and intercept were significantly different from 0 at $p<0.001$

cient number of high quality electron micrographs to measure a large number of pores.

\section{DISCUSSION}

The functions of the food-concentrating filter and pharyngeal filter must be considered together to understand the feeding mechanism of oikopleurids. The pharyngeal filter of Oikopleura vanhoeffeni had a mean pore size and fiber diameter that was much larger than that of the food-concentrating filter (compare Table 1 to data in Deibel et al. 1985). Mean pore width and length of the pharyngeal filter were about 15 times and 6 times larger, respectively, than corresponding dimensions of the food-concentrating filter. Thus, the pores of the pharyngeal filter were more 'square' in shape than were the pores of the foodconcentrating filter. The mean width-to-length ratio of the pharyngeal filter pores was 0.55 , while the same ratio for the food-concentrating filter was 0.22 (Deibel et al. 1985). However, the fibers of the pharyngeal filter were proportionately larger than were those of the food-concentrating filter, so that the mean porosity of both filters was $91 \%$ (Deibel et al. 1985). 
However, there were several differences in the ultrastructure of the pharyngeal filter in comparison to that of the food-concentrating filter (Deibel et al. 1985). The pharyngeal filter was of a simpler design, with fibers of uniform diameter rather than fibers of 3 different diameters. This undoubtedly reflects the differing complexity of the types of cells that secrete the filters. The food-concentrating filter is secreted by a complex of specialized oikoplast epithelial cells (Körner 1952), while the pharyngeal filter is secreted by an apparently simpler group of endostyle cells (Fenaux 1968). Also, the lack of nodes and appearance of overlapping in pharyngeal filter fibers is at odds with the presence of nodes and apparent linking of the protein core of fibers in the food-concentrating filter (Flood 1981) and may account for the much higher variance of pore size of the pharyngeal filter.

We are aware of no published information on the retention index ( $R$ ) and apparent maximum mesh width (AMMW) of a pelagic tunicate filter determined using ultrastructural information. However, Harbison \& McAlister (1979) have empirically determined $\mathrm{R}$ and AMMW for some oceanic salps by feeding them particles from a wide size range. There was little difference between the 3 methods for calculating $\mathrm{R}$ and AMMW of Oikopleura vanhoeffeni, and no grounds for preferring a particular theoretical model (Table 2). A similar conclusion was reached by Harbison \& McAlister (1979) for Cyclosalpa sp. Predicted R and AMMW of the pharyngeal filter of $O$. vanhoeffeni (Table 2) are at the upper end of the range of values of 3 species of Cyclosalpa studied by Harbison \& McAlister (1979; $\mathrm{R}=1.3$ to $3.5 \mu \mathrm{m}, \mathrm{AMMW}=1.7$ to $4.6 \mu \mathrm{m}$ ). Also, the values of the ratio $A M M W / R$ for $O$. vanhoeffeni (Table 2) extend beyond the range of values of Cyclosalpa (1.3 to 1.9; Harbison \& McAlister 1979). This means that the slope of the relative cumulative frequency distribution of pore widths of $O$. vanhoeffeni is somewhat lower than is the slope of \% retention versus particle size for the salps. These differences in retention characteristics may be real, reflecting adaptation of $O$. vanhoeffeni to a subarctic, coastal environment, with seasonal abundance of large particles during the spring diatom increase, versus adaptation of Cyclosalpa to a warm water, open ocean environment dominated by small particles. However, the above prediction for $O$. vanhoeffeni is dependent on the pharyngeal filter functioning primarily as a sieve. If direct interception and adhesion of particles to pharyngeal filter fibers is important, $R$ will be shifted to smaller values in experimental determinations of particle retention efficiency. These experiments have yet to be done with $O$. vanhoeffeni.

Salps consume suspended bacteria using their mucous filters, but do so with reduced efficiency in com- parison to their consumption of larger phytoflagellates (Harbison \& Gilmer 1976, Harbison \& McAlister 1979, Mullin 1983). However, it has been suggested that oikopleurid appendicularians may retain suspended bacteria and nanoflagellates with similar efficiency (King et al. 1980), and that because the food-concentrating filter is composed of mesh with very small pores their consumption of particles with nominal sizes of $0.1 \mu \mathrm{m}$ is high (Flood 1978). However, the filter actually responsible for removing food particles from suspension, the pharyngeal filter, seems to be sufficiently coarse that particles of $<1.0 \mu \mathrm{m}$ will be retained with $<10 \%$ efficiency (Fig. 4). This is less than retention efficiencies of this particle size found for salps $(20 \%$; Harbison \& McAlister 1979). The belief that oikopleurids efficiently remove particles of $0.1 \mu \mathrm{m}$ from suspension (Flood 1978) is based on the assumption that the food-concentrating filter functions as a particle trap and that particles trapped by this filter are ingested directly. My observations of Oikopleura vanhoeffeni (Deibel in press), and those of other oikopleurids by Alldredge (1977), indicate that this is not the case. Although the food-concentrating filter may retain particles of $0.1 \mu \mathrm{m}$ and larger, the concentrated suspension must be processed by the pharyngeal filter before the particles are ingested. We predict that these small particles will not be retained efficiently by the pharyngeal filter. This prediction agrees with the only experimental determination of the retention efficiency spectrum of an oikopleurid of which we know. Paffenhöfer (pers. comm.) found that the small, warmocean Oikopleura dioica retains particles from 3 to $6 \mu \mathrm{m}$ in size with maximum efficiency.

Different modes of mucous net feeding (i.e. ciliary vs muscular) have different values for the pressure drop across the filter, which is an estimate of filter resistance (Jørgensen 1983, Jørgensen et al. 1984). Invertebrates that use muscles to pump water have pressure drops of 1 to $2 \mathrm{~mm} \mathrm{H}_{2} \mathrm{O}$, while those using cilia have pressure drops $1 / 10$ as high (0.1 to $0.2 \mathrm{~mm} \mathrm{H}_{2} \mathrm{O}$; Jørgensen 1983). Knowing the pressure drop across a filter and its retention efficiency spectrum allows one to quantify the flund mechanics of particle collection and to predict removal rates of particles of various sizes. We now have sufficient information to make a first-order estimate of the pressure drop across the pharyngeal filter of Oikopleura vanhoeffeni.

An individual Oikopleura vanhoeffeni of average trunk length $(2.5 \mathrm{~mm})$ has a clearance rate, or rate of pumping water through its house, of $1560 \mathrm{ml} \mathrm{d}^{-1}$ $\left(\mathrm{CR}=12.6\right.$ trunk length $[\mathrm{mm}]^{1.79} \mathrm{ml} \mathrm{h}^{-1}, \mathrm{n}=25$; in situ latex microsphere technique, Deibel unpubl.). Assuming that oikopleurids exclude about $99 \%$ of the total volume of water pumped through the house while concentrating the food suspension in the food-concen- 
trating filter (Jørgensen 1984), approximately $16 \mathrm{ml}$ $\mathrm{d}^{-1}$ remains to be passed through the pharyngeal filter. The pharyngeal filter is a right circular cone of length (i.e. height, h) equal to approximately 0.75 of the trunk length of the individual (excluding gonad: calculated from measurements of Fig. 1), and diameter (d) equal to the diameter of the mouth (about $0.2 \mathrm{~mm}$; Fig. 1). In this case, given that $\mathrm{h}=1.88 \mathrm{~mm}$ and $\mathrm{d}=0.20 \mathrm{~mm}$, the lateral surface area $(\mathrm{A})$ of the pharyngeal filter is $6 \times 10^{-1} \mathrm{~mm}^{2}\left[\mathrm{~A}=\pi(\mathrm{d} / 2) \sqrt{(\mathrm{d} / 2)^{2}}+\mathrm{h}^{2}\right]$. To pass $16 \mathrm{ml} \mathrm{d}^{-1}$ through a filter of this surface area requires a flow velocity of about $0.3 \mathrm{~mm} \mathrm{~s}^{-1}$, similar to that through ascidian and gastropod mucous nets (ciliary pumping mechanisms, 0.4 to $0.8 \mathrm{~mm} \mathrm{~s}^{-1}$ ), but much lower than that through the mucous net of polychaetes (muscular pumping mechanism, $3 \mathrm{~mm} \mathrm{~s}^{-1}$; Jørgensen et al. 1984). This agrees with the accepted view of the feeding mechanism of oikopleurids, for although flow through the food-concentrating filter is driven by the muscular tail, flow through the pharyngeal filter is largely due to suction of water from the pharyngeal cavity by cilia of the spiracles (Alldredge 1977, Deibel in press).

We used the modified Darcy equation to calculate the pressure drop across the pharyngeal filter of Oikopleura vanhoeffeni (Jørgensen et al. 1984);

$$
\mathrm{dp}=8 \pi \eta \mathrm{U}_{0} / \mathrm{b}\left(1-2 \ln \tau+1 / 6 \mathrm{t}^{2}\right)
$$

where $\tau=\pi(d / b)$, with $d=$ diameter of the fibers (cm), and $\mathrm{b}=$ center distance between neighboring fibers $(\mathrm{cm}) ; \eta=$ absolute viscosity $\left(1.885 \times 10^{-2} \mathrm{~g} \mathrm{~cm}^{-1} \mathrm{~s}^{-1}\right.$ at $0^{\circ} \mathrm{C}$ and $30 \%$ ); and $\mathrm{U}_{0}=$ unrestricted flow velocity $\left(\mathrm{cm} \mathrm{s}^{-1}\right)$. Using the mean pore size and fiber diameter from Table 1, and the above flow velocity of $0.03 \mathrm{~cm}$ $5^{-1}$, the pressure drop across the pharyngeal mucous net was 13.7 dynes $\mathrm{cm}^{-2}$, or $0.14 \mathrm{~mm} \mathrm{H} \mathrm{H}_{2} \mathrm{O}(1 \mathrm{~mm}$ $\mathrm{H}_{2} \mathrm{O}=97.8$ dynes $\mathrm{cm}^{-2}$ ). This is the total pressure drop resulting from the sum of the pressure drops across the longitudinal and transverse fibers. This pressure drop is less than that estimated across the mucous filter of the polychaete Chaetopterus variopedatus $10.7 \mathrm{~mm}$ $\mathrm{H}_{2} \mathrm{O}$, muscular pumping mechanism) but is similar to that estimated across the mucous filters of the gastropod Crepidula fornicata $\left(0.2 \mathrm{~mm} \mathrm{H}_{2} \mathrm{O}\right)$ and the ascidian Ascidia mentula $\left(0.1 \mathrm{~mm} \mathrm{H}_{2} \mathrm{O}\right.$, both have a ciliary pumping mechanism; Jørgensen et al. 1984). Once again, this indicates that flow through the pharyngeal filter of $O$. vanhoeffeni is typical of flow driven by cilia.

These calculations are based on several assumptions that are as yet poorly quantified. The amount of water excluded during concentration of food $199 \%$ of the total taken into the house) has been estimated only roughly (Jørgensen 1984). More detailed study of rates of flow at the surface of the food-concentrating filter and pharyngeal filter remains to be done. The pharyngeal filter is not naturally relaxed and static as it is when fixed for transmission electron microscopy, but is under hydrostatic pressure and is continuously moving, i.e. it is continuously produced and ingested. Therefore, the rate of flow at the surface of the pharyngeal filter depends on the relative velocity of water and filter, and may not be represented correctly by our simple model used above of throughflow and filter area. Likewise, pore size is likely to be different when the filter is under pressure than when it is relaxed. If this is true, the experimentally determined retention efficiency spectrum will differ from that predicted based on the ultrastructure of the filter (see above). These assumptions need to be evaluated experimentally. We can conclude at this time that a pressure drop of $0.14 \mathrm{~mm} \mathrm{H}_{2} \mathrm{O}$ is reasonable given what is known about the ciliary component of the feeding mechanism of oikopleurid appendicularians.

The Reynold's number (Re), which is unitless, expresses the relation between inertial and viscous flow past a fixed body. Re can be calculated for a single fiber of the pharyngeal filter by

$$
\operatorname{Re}=6 \mathrm{aU}_{0} / \eta
$$

where $\mathrm{a}=$ fiber diameter $\left(2.03 \times 10^{-5} \mathrm{~cm}\right)$; and $\eta$ and $\mathrm{U}_{0}\left(3.0 \times 10^{-2} \mathrm{~cm} \mathrm{~s}^{-1}\right)$ are defined as in the previous paragraph. The resulting $\operatorname{Re}$ number is $3.2 \times 10^{-5}$, indicating that flow through the pharyngeal filter is laminar and is dominated by viscous rather than inertial forces. This means that particle motion is coupled tightly to fluid flow, and that particles do not coast when the fluid is brought to rest, such as when Oikopleura sp. stops pumping to backflush its incurrent filters. This Re number is similar to those of nanoflagellates, ciliates, bivalves, and ascidians, but is larger than those of sponges $\left(10^{-7}\right)$, and smaller than those of calanoid copepods $\left(10^{-2}\right.$; Jorgensen 1983). The Re number is important because it can be used to calculate the boundary layer of no motion around filter fibers, which is pertinent to understanding the resistance of the pharyngeal filter to flow.

Our predictions of functional aspects of particle retention based on the ultrastructure of the pharyngeal filter will allow us to test specific hypotheses about particle size selection by Oikopleura vanhoeffeni (Table 2; Fig. 4), and to detect fixation artifacts introduced by preparation of the filter for transmission electron microscopy. Future studies of oikopleurid feeding should focus on the structure and function of the pharyngeal filter, for it is ultimately responsible for removing particles from suspension. If oikopleurids generally have pharyngeal filters of coarse mesh, then we will have to re-evaluate their importance as consumers of picoplankton, ultraplankton, and suspended bacteria. 
Acknowledgements. We thank the members of the MSRL Diving Unit for assisting DD with the collection of Oikopleura vanhoeffeni, and the Department of Biology, Memorial University of Newfoundland, for the use of electron microscope facilities. We are grateful to Dr. C. B. Jørgensen, and 2 anonymous reviewers, for making constructive comments on an earlier draft and correcting several errors in our formulations. Special thanks go to Dr. J. T. Turner for making available the scanning electron micrograph (Fig. 2). Mr. S. H. Lee drafted the figures, and Mr. R. Ficken did the darkroom work. This research was supported by both Operating and Equipment Grants to DD from the Natural Sciences and Engineering Research Council of Canada. This is Marine Sciences Research Laboratory contribution no. 662, and Newfoundland Institute for Cold Ocean Science contribution no. 124.

\section{LITERATURE CITED}

Alldredge, A. L. (1977). House morphology and mechanisms of feeding in the Oikopleuridae (Tunicata, Appendicularia). J. Zool., Lond. 181: 175-188

Alldredge, A. L., Madin, L. P. (1982). Pelagic tunicates: unique herbivores in the marine plankton. Bioscience 32 (8): 655-663

Cassie, R. M. (1955). The escapement of small fish from trawl nets and its application to the management of the New Zealand snapper fisheries. N.Z. Mar. Dept. Fish. Bull. 11: $1-99$

Deibel, D. (in press). Feeding mechanism and house of the cold ocean appendicularian Oikopleura vanhoeffeni. Mar. Biol.

Deibel, D., Turner, J. T (1985). Zooplankton feeding ecology: contents of fecal pellets of the appendicularian Oikopleura vanhoeffeni. Mar. Ecol. Prog. Ser. 27: 67-78

Deibel, D., Dickson, M.-L., Powell, C. V. L. (1985). Ultrastructure of the mucous feeding filter of the house of the appendicularian Oikopleura vanhoeffeni. Mar. Ecol. Prog. Ser. 27: 79-86

Fenaux, R. (1968). Le mécanisme alimentaire chez les tuniciers. Ann. Biol. 7 (7-8): 345-367

Flood, P. R. (1978). Filter characteristics of appendicularian food catching nets. Experientia 34: 173-175

Flood, P. R. (1981). On the ultrastructure of mucus. Biomed. Res. 2: 49-53

Flood, P. R., Fiala-Médioni, A. (1981). Ultrastructure and histochemistry of the food trapping mucous film in benthic filter-feeders (Ascidians). Acta zool., Stockh. 62: 53-65

Harbison, G. R., Gilmer, R. W. (1976). The feeding rates of the pelagic tunicate Pegea confoederata and two other salps. Limnol. Oceanogr. 21: 917-928

Harbison, G. R., McAlister, V L. (1979). The filter-feeding rates and particle retention efficiencies of three species of Cyclosalpa (Tunicata, Thaliacea). Limnol. Oceanogr 24: 875-892

Jørgensen, C. B. (1983). Fluid mechanical aspects of suspension feeding. Mar. Ecol. Prog. Ser 11: 89-103

Jorgensen, C. B. (1984). Effect of grazing: Metazoan suspension feeders. In: Hobbie, J. E., Williams, P. J. leB. (ed.) Heterotrophic activity in the sea. Plenum Press, New York and London, p. 445-464

Jørgensen, C. B., Kiørboe, T., Møhlenberg, F., Riisgård, H. U. (1984). Ciliary and mucus-net filter feeding, with special reference to fluid mechanical characteristics. Mar. Ecol. Prog. Ser. 15: 283-292

Körner, W. F. (1952). Untersuchungen über die Gehäusebildung bei Appendicularien (Oikopleura dioica Fol.). Z. Morph. Ókol. Tiere 41: 1-53

King, K. R., Hollibaugh, J. T., Azam, F. (1980). Predator-prey interactions between the larvacean Oikopleura dioica and bacterioplankton in enclosed water columns. Mar. Biol. 56: $49-57$

Monniot, F. (1979). Microfiltres et ciliatures branchiales des ascidies littorales en microscopie électronique. Bull. Mus. Hist. nat., Paris 4: 843-859

Mullin, M. M. (1983). In situ measurement of filtering rates of the salp Thalia democratica, on phytoplankton and bacteria. J. Plankton Res. 5: 279-289

Pennachetti, C. A. (1984). Functional morphology of the branchial basket of Ascidia paratropa (Tunicata, Ascidiacea). Zoomorph. 104: 216-222

Ray, A. A. (ed.) (1982). SAS user's guide: statistics 1982 edition. SAS Institute, Cary, North Carolina

Silver, M. W., Bruland, K. W. (1981). Differential feeding and fecal pellet composition of salps and pteropods, and the possible origin of the deep-sea flora and olive-green 'cells' Mar. Biol. 62: 263-273

Sokal, R. R., Rohlf, F. J. (1982) Biometry. W. H. Freeman and Co., San Francisco

Wallace, J. B., Malas, D. (1976). The significance of the elongate, rectangular mesh found in capture nets of fine particle filter feeding Trichoptera larvae. Arch. Hydrobiol. 77. 20.5-212 